\title{
Permeation of Gases through Electron-Beam-Irradiated Polymer Films
}

\author{
Hidetoshi KITA, Michiaki MuraOKA, Kazuhiro TANAKA, \\ and Ken-ichi OKAмото \\ Department of Chemical Engineering, Faculty of Engineering, \\ Yamaguchi University, Ube, Yamaguchi 755, Japan
}

(Received August 10, 1987)

\begin{abstract}
The permeation of $\mathrm{CO}_{2}, \mathrm{CH}_{4}, \mathrm{O}_{2}, \mathrm{~N}_{2}, \mathrm{SF}_{6}$, and $\mathrm{He}$ was measured at $35^{\circ} \mathrm{C}$ in electron-beam-irradiated polymer films such as 1,2-polybutadiene (PB), polycarbonate (PC), polydimethylsiloxane (PDMS), poly(ethylene terephthalate) (PET), poly(4-methylpentene-1) (PMP), and polypropylene (PP). The permeability coefficients of the gases in PB decreased and those in PP increased with increasing irradiation dose, while those of PC, PDMS, PET, and PMP were virtually unaffected by irradiation. These results were attributed to the radiation effects of crosslinking in PB and degradation in PP. PC, PDMS, PET, and PMP were insensitive to radiation, which accounts for the little change in permeation behavior. The decreases in permeability coefficients of the gases in irradiated PB films were attributed to changes in diffusivity, while solubility was not greatly affected. The dependence of permeability coefficients on crosslinking density of the irradiated PB films was also discussed. Decreases in permeability and diffusion coefficients were interpreted as due to decrease of free-volume content by crosslinking. The diffusion coefficient showed an approximately exponential relationship to the reciprocal of the average molecular weight between crosslinks $\left(\bar{M}_{\mathrm{c}}\right)$ over a range of $\bar{M}_{\mathrm{c}}$ between 200 and 20000 . This suggests that the free-volume of the crosslinked polymer may be proportional to $\bar{M}_{\mathrm{c}}$.

KEY WORDS Electron Beam Irradiation / Radiation Induced Crosslinking / Permeability Coefficient / Diffusion Coefficient / Free-Volume / Crosslinking Density / 1,2-Polybutadiene /
\end{abstract}

Industrial applications of electron beam radiation have been well established in the plastics industry, for instance, crosslinking of polyethylene and poly(vinyl chloride) by electron processing, rubber latex vulcanization, and paint coat curing. Crosslinking of a polymer results in a significant increase in the mechanical strength and the heat resistance. These improved properties make this processing attractive in the development of efficient polymer membranes for gas separation. However, studies of the effects of ionizing irradiation on the gas transport properties are limited to a few polymer systems, polyethylene and poly(tetrafluoroethylene). ${ }^{1-5}$ The effects of crosslinking on the gas transport properties through polymer film have been mostly investigated in chemically crosslinked systems. $^{6-11}$ The major conclusions of these studies are that crosslinking causes reduction in gas permeability. The correlation of gas transport properties with the average molecular weight or average chain-length between crosslinks, however, has not been fully understood yet.

We report here permeation behavior of gases through electron-beam-irradiated polymer films. The polymers used were 1,2-polybutadiene (PB), polycarbonate (PC), polydimethylsiloxane (PDMS), poly(ethylene terephthalate) (PET), poly(4-methylpentent-1) (PMP), and polypropylene (PP). The number 
Table I. Polymers and gases used

\begin{tabular}{llc}
\hline Polymers & Supplier & Thickness $/ \mu \mathrm{m}$ \\
\hline 1,2-Polybutadiene (PB) & Japan Synthetic Rubber Co. (RB810) & \\
Polycarbonate (PC) & Matsubishi Gas Chemical Co. (Iupilon) & 50 \\
Polydimethylsiloxane (PDMS) & Shin-etsu Chemical Co. (KE42SRTV) & 12 \\
Poly(ethylene terephthalate) (PET) & Toray Industries (Lumilar S10) & 50 \\
Poly(4-methylpentene-1) (PMP) & Mitsui Petrochemical Industries (TPX-44) & 22 \\
Polypropylene (PP) & Toray Industries (Torefan T2400) & Purity/\% \\
\hline Gases & Supplier & 99.995 \\
\hline $\mathrm{He}$ & Taiyo Sanso Co. & 99.995 \\
$\mathrm{~N}_{2}$ & Osaka Sanso Co. & 99.9 \\
$\mathrm{CO}_{2}$ & Seitetsu Chemical Co. & 99.5 \\
$\mathrm{SF}_{6}$ & Seitetsu Chemical Co. & 99.9 \\
$\mathrm{O}_{2}$ & Seitetsu Chemical Co. & 99.9 \\
$\mathrm{CH}_{4}$ & Seitetsu Chemical Co. & \\
\hline
\end{tabular}

average molecular weight between the crosslinks of electron-beam-irradiated PB was estimated and correlated with the transport characteristics of various gases.

\section{EXPERIMENTAL}

The polymers used in this study are listed in Table I. PB and PDMS films were obtained by casting from toluene solutions on glass plates under reduced pressure and were dried under vacuum for at least $24 \mathrm{~h}$. Other polymer films were used as received.

Electron beam radiations were performed in nitrogen atmosphere at doses of $1-80 \mathrm{Mrad}$ at room temperature using Nissin-High Voltage Area-beam-type electron processing system. The accelerating voltage of electron beam was maintained at $200 \mathrm{kV}$.

The extent of crosslinking was estimated by measuring the gel fraction. The gel fraction was determined by extraction with boiling toluene for $24 \mathrm{~h}$ and measuring the weight loss. Longer extraction times did not result in further loss of weight. The extracted samples were dried to constant weight in a vacuum oven at $50^{\circ} \mathrm{C}$ for $24 \mathrm{~h}$.

Gases of purity exceeding $99.5 \mathrm{vol} \%$ were used (Table I). The permeability measure- ments for unirradiated and irradiated polymer films were made by a nonequable pressure method, where the low pressure side of the sample was maintained near atmospheric pressure and the transmission of the gas was measured by change in volume. The permeability coefficients were calculated from steady-state permeation rates. The diffusion coefficients were evaluated using the high vacuum time-lag technique introduced by Barrer. $^{12}$ Experimental runs were carried out in a pressure range of $10^{5}-10^{6} \mathrm{~Pa}$ at $35 \pm 0.1^{\circ} \mathrm{C}$. Permeability coefficients were found to be independent of pressure under the experimental conditions.

\section{RESULTS AND DISCUSSION}

Figure 1 shows permeability coefficients $P$ of $\mathrm{CO}_{2}$ in irradiated polymer films as a function of irradiation dose. The permeability coefficients for PB decreased with increasing irradiation dose, while those for PC, PDMS, PET, and PMP were virtually unaffected by irradiation. In the case of $\mathrm{PP}, \mathrm{CO}_{2}$ permeated through 20 Mrad-irradiated films about 50 times faster than through unirradiated ones. The similar dependence of the permeability coefficient on irradiation dose was observed in 
the permeation of gases, $\mathrm{He}, \mathrm{N}_{2}$, and $\mathrm{SF}_{6}$. With high-energy irradiation, it is well known that polymers simultaneously crosslink and are degraded. ${ }^{13}$ These results, therefore, are

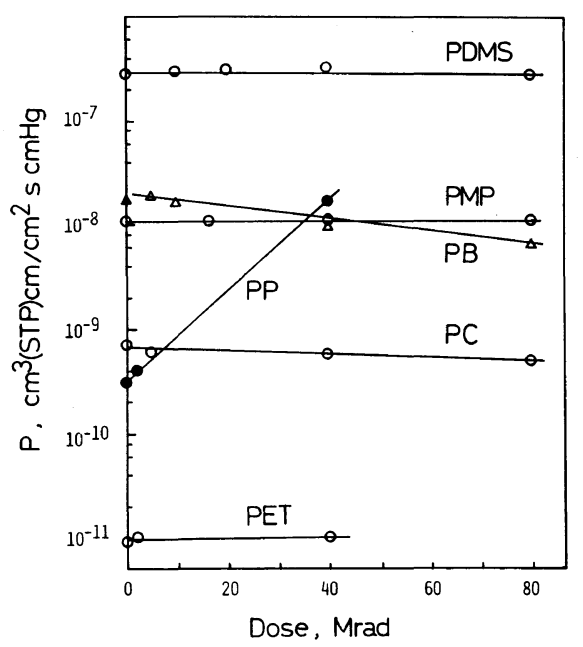

Figure 1. The effects of irradiation dose on the permeability coefficients of $\mathrm{CO}_{2}$ gas through irradiated polymer films at $35^{\circ} \mathrm{C}$. attributed to the combined radiation effects of crosslinking and chain scission of polymers.

In the case of irradiated PP, oxidative degradation occurs with increasing dose. ${ }^{13}$ From the infrared analysis, carbonyl absorption at $1740 \mathrm{~cm}^{-1}$ increased with irradiation. The GPC data showed that the number average molecular weight, $\bar{M}_{n}$, of the starting PP polymer $\left(\bar{M}_{n}=9.49 \times 10^{4}\right)$ decreases to onefourth $\left(\bar{M}_{n}=2.16 \times 10^{4}\right)$ when irradiated at 20 Mrad. The tensile strength of PP also decreased with dose. Thus, PP undergoes chain scission of the polymer main chain when exposed to an electron beam, and the scission causes an increase of the permeability coefficient. Similar results have been reported by Tikhomirova et $\mathrm{al}^{3}$ for polytetrafluoroethylene exposed to gamma-ray irradiation. On the other hand, PC, PDMS, PET, and PMP are resistant to radiative degradation, which accounts for little change of permeation behavior.

In the case of $\mathrm{PB}$, the electron-beam irra-

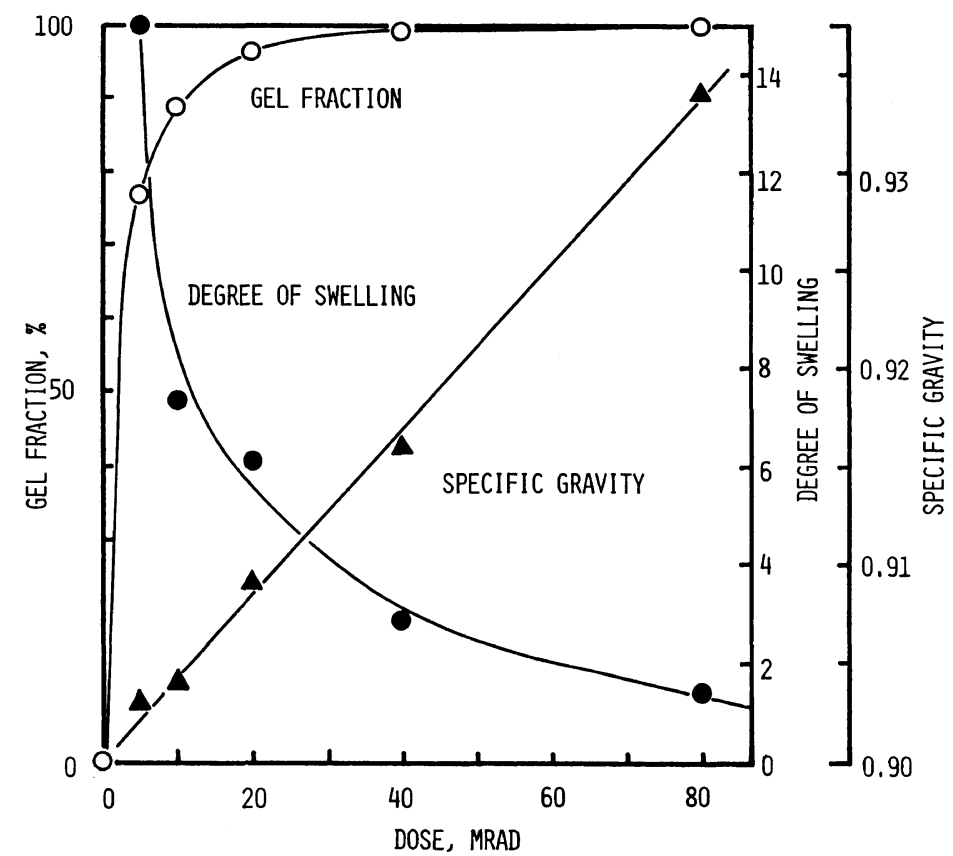

Figure 2. Gel fraction, degree of swelling in toluene, and specific gravity as a function of the irradiation dose for polybutadiene films. 


\section{H. KiTA et al.}

Table II. Permeability coefficients $(P)$, diffusion coefficients $(D)$, and solubility coefficients $(S)$ for unirradiated and irradiated $\mathrm{PB}$ films at $35^{\circ} \mathrm{C}$

\begin{tabular}{|c|c|c|c|c|c|c|c|c|c|}
\hline \multirow{2}{*}{ Gas } & \multicolumn{3}{|c|}{$10^{10} P\left(\mathrm{~cm}^{3}(\mathrm{STP}) \mathrm{cm} \mathrm{cm}^{-2} \mathrm{~s}^{-1} \mathrm{cmHg}^{-1}\right)$} & \multicolumn{3}{|c|}{$10^{6} D\left(\mathrm{~cm}^{2} \mathrm{~s}^{-1}\right)$} & \multicolumn{3}{|c|}{$10^{4} S\left(\mathrm{~cm}^{3}(\mathrm{STP}) \mathrm{cm}^{-3} \mathrm{cmHg}^{-1}\right)$} \\
\hline & $0 \mathrm{Mrad}$ & $40 \mathrm{Mrad}$ & $80 \mathrm{Mrad}$ & $0 \mathrm{Mrad}$ & $40 \mathrm{Mrad}$ & $80 \mathrm{Mrad}$ & $0 \mathrm{Mrad}$ & $40 \mathrm{Mrad}$ & $80 \mathrm{Mrad}$ \\
\hline $\mathrm{O}_{2}$ & 21.9 & 19.7 & 7.42 & 2.00 & 2.02 & 1.05 & 11.0 & 9.90 & 7.80 \\
\hline $\mathrm{N}_{2}$ & 6.71 & 5.33 & 1.60 & 1.44 & 1.18 & 0.396 & 4.68 & 4.52 & 4.06 \\
\hline $\mathrm{CO}_{2}$ & 134 & 112 & 36.9 & 1.58 & 1.40 & 0.369 & 85.0 & 80.1 & 99.9 \\
\hline $\mathrm{CH}_{4}$ & 20.3 & 15.7 & 4.01 & 0.695 & 0.590 & 0.144 & 29.3 & 26.6 & 27.8 \\
\hline $\mathrm{SF}_{6}$ & 0.772 & 0.524 & 0.105 & 0.0306 & 0.0180 & & 25.2 & 28.0 & \\
\hline
\end{tabular}

diation readily causes a crosslinking reaction. Figure 2 shows gel fraction, degree of swelling in toluene and density as a function of irradiation dose for electron-beam-irradiated $\mathrm{PB}$ films. The PB film gelled to the extent of $90 \%$ when irradiated to $10 \mathrm{Mrad}$. The permeability coefficients of test gases in irradiated PB films as a function of irradiation dose are shown in Figure 3. Permeability coefficients decrease with the irradiation. The permeability of a gas through a polymer film depends on both the diffusivity and the solubility. Therefore, the individual contributions of both factors toward the permeability should be considered. As described before, the time-lag method was used to determine the diffusion coefficients $D$, and the solubility coefficients $S$ were calculated from the relationship $P=D \cdot S$. The results are shown in Table II for irradiated and unirradiated PB films. Diffusivity of $\mathrm{He}$ was so high that $D$ could not be evaluated by the timelag method. The diffusion coefficients decreased with irradiation, while the solubility coefficients were not greatly affected. This is consistent with the results reported by Barrer and others. ${ }^{6.8}$ It has been reported that the solubility coefficients of permanent gases in vulcanized rubber ${ }^{6}$ and highly crosslinked copolymer of ethylacrylate and tetraethyleneglycol $^{8}$ show little dependence on crosslinking density. Figure 4 shows the relationship between the ratios of permeability coefficients for irradiated and unirradiated PB films and those of diffusion coefficients for irradiated and un-

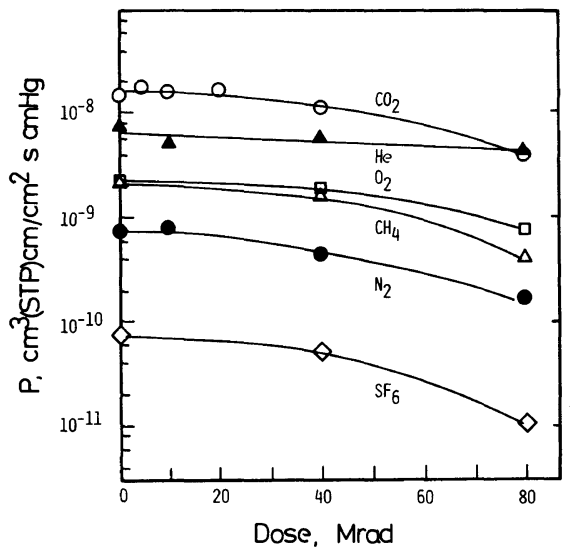

Figure 3. The effects of irradiation dose on the permeability coefficients of the test gases through irradiated polybutadiene films at $35^{\circ} \mathrm{C}$.

irradiated ones. It can be seen that there is a correlation between the two ratios. Thus, the reduction in permeability is considered to reflect primarily changes in diffusion.

In early studies $^{7-11}$ with gamma-rayirradiated polymers the number average molecular weight between crosslinks, $\bar{M}_{\mathrm{c}}$, or chainlength distribution was not always determined. For irradiated PB, $\bar{M}_{\mathrm{c}}$ was determined from the data shown in Figure 2 by the relation of Flory, ${ }^{14}$ namely.

$$
\begin{aligned}
- & {\left[\ln (1-v)+v+\chi v^{2}\right] } \\
= & \left(V_{1} / \bar{v} \bar{M}_{\mathrm{c}}\right)\left(1-2 \bar{M}_{\mathrm{c}} / \bar{M}_{n}\right)\left(v^{1 / 3}-v / 2\right)
\end{aligned}
$$

where $v$ is the volume ratio of the crosslinked polymer before and after swelling, $\chi(=0.3587)$ 


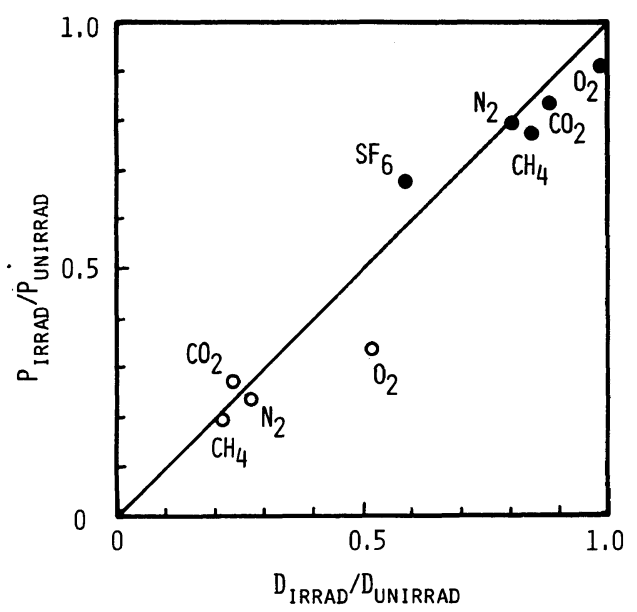

Figure 4. Relationship between the ratios of permeability coefficients for irradiated and unirradiated PB films $\left(P_{\text {irrad }} / P_{\text {unirrad }}\right)$ and those of diffusion coefficients for irradiated and unirradiated ones $\left(D_{\text {irrad }} / D_{\text {unirrad }}\right)$ : (O), 40 Mrad; (O), 80 Mrad.

the interaction parameter of PB-toluene, ${ }^{15} V_{1}$ the molar volume of toluene, $\bar{v}$ the specific volume of irradiated $\mathrm{PB}$, and $\bar{M}_{n}$ the number average molecular weight (71000). The values of $\bar{M}_{\mathrm{c}}$, crosslinking density, and number of links between crosslinks are shown in Table III. Figure 5 illustrates the effects of the degree of crosslinking, as indicated by the average molecular weight between crosslinks, on permeability coefficients for various gases. The values of permeability coefficient for the gases decreased with the decreasing $\bar{M}_{\mathrm{c}}$ at $\bar{M}_{\mathrm{c}}$ less than about $10^{3}$, while those at higher $\bar{M}_{\mathrm{c}}$ were almost constant. This result suggests that permeation characteristics of the film are little affected by crosslinking density until the polymer is highly crosslinked. Furthermore, with highly crosslinked networks the dependence of the permeability coefficient on crosslinking density becomes greater as the size of the penetrant increases. The PB films irradiated at $80 \mathrm{Mrad}\left(\bar{M}_{\mathrm{c}} \fallingdotseq 200\right)$ had lower permeability coefficients for $\mathrm{SF}_{6}$ than uniradiated films by a factor of about 10 , whereas the permeability coefficient of $\mathrm{He}$ only decreased by a factor of less than 2 . It is to be noted that a small
Table III. Network parameters of electron-beamcrosslinked PB

\begin{tabular}{|c|c|c|c|}
\hline Dose & $\bar{M}_{\mathrm{c}}$ & $\begin{array}{c}\text { Crosslinking } \\
\text { density }\left(10^{4} \rho_{x}\right)^{\mathrm{a}}\end{array}$ & $\begin{array}{l}\text { Number of links } \\
\text { (C-C bonds) }\end{array}$ \\
\hline Mrad & $\mathrm{g} \mathrm{mol}^{-1}$ & $\mathrm{~mol} \mathrm{~cm}^{-3}$ & $\begin{array}{l}\text { between two } \\
\text { crosslinks }(u)^{b}\end{array}$ \\
\hline 0 & $71000^{c}$ & & \\
\hline 10 & 8900 & 0.761 & 165 \\
\hline 20 & 6600 & 1.11 & 123 \\
\hline 40 & 1360 & 6.45 & 25.2 \\
\hline 80 & 153 & 60.8 & 2.8 \\
\hline
\end{tabular}

a $\rho_{x}=\rho / \bar{M}_{\mathrm{c}}$.

b $u=\bar{M}_{\mathrm{c}} / M_{\mathrm{r}}$, where $M_{\mathrm{r}}$ is the molecular weight of the PB repeating unit $\left(M_{\mathrm{r}}=54\right)$.

c $\bar{M}_{n}$.

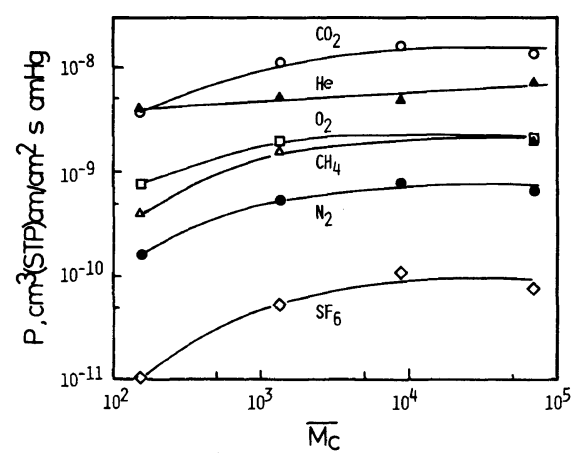

Figure 5. Dependence of the permeability coefficient on the average molecular weight between crosslinks, $\bar{M}_{\mathrm{c}}$, in irradiated polybutadiene.

molecule can permeate through crosslinked networks of PB having between 200 and 20000. In the permeation of large molecules, however, a large reduction in the permeability was observed in the same region of $\bar{M}_{\mathrm{c}}$.

The dependence of permeability and diffusion coefficients on $\bar{M}_{\mathrm{c}}$ is quite different from uncrosslinked systems. The permeability coefficients in $\mathrm{CO}_{2}$ and $\mathrm{O}_{2}$-polystyrene systems decrease with increasing molecular weight ${ }^{16}$ for molecular weight in a range less than $10^{5}$. This effect has been attributed to excess freevolume associated with the high concentration of chain ends in low-molecular-weight polymers. In the present case, chain mobility and flexibility were greatly reduced when the poly- 


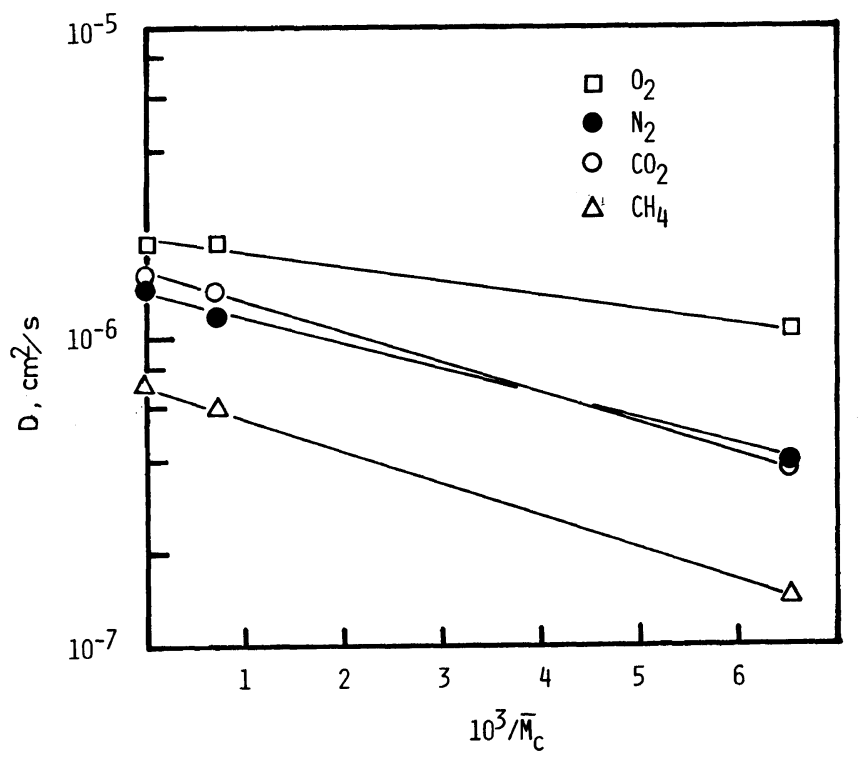

Figure 6. Plots of $\ln (D)$ against $1 / \bar{M}_{\mathrm{c}}$.

mer chains crosslinked more with an increase in irradiation dose, resulting in a decrease in permeability and diffusion coefficients.

From the exponential relationship between permeability coefficients and $\bar{M}_{\mathrm{c}}$ as shown in Figure 5, it is assumed that there is a linear dependence between the logarithum of diffusion coefficients and $1 / \bar{M}_{\mathrm{c}}$, while Barrer $e t$ $a l .{ }^{17}$ reported the linear relationship between $D$ and $1 / \bar{M}_{\mathrm{c}}$ on vulcanized rubber over a range of $\bar{M}_{\mathrm{c}}$ between 5000 and 25000 . The correlations of $\ln (D)$ with $1 / \bar{M}_{\mathrm{c}}$ are shown in Figure 6 over a range of $\bar{M}_{\mathrm{c}}$ between 200 and 20000 , although the number of data points is not enough. This is rather interesting and needs additional experiments. One possible explanation at the present time is that the freevolume fraction of the crosslinked polymer may be proportional to $\bar{M}_{\mathrm{c}}$.

According to the free-volume theory, ${ }^{18}$ the diffusion coefficient is given by the equation

$$
D=A R T \exp \left(-B / V_{\mathrm{f}}\right)
$$

where $R$ is the universal gas constant, $T$ the absolute temperature, $v_{\mathrm{f}}$ the free-volume fraction of the polymer, and $A$ and $B$ constants

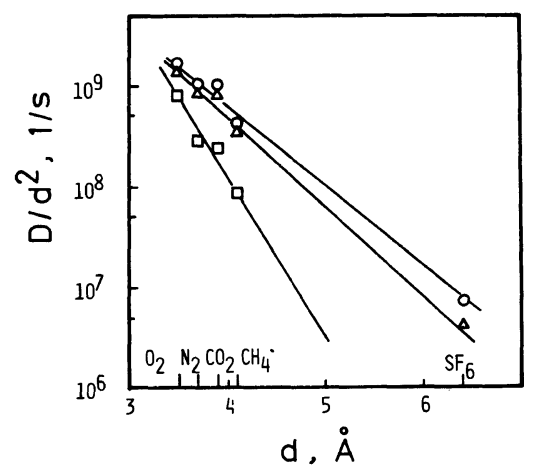

Figure 7. Plots of $\ln \left(D / d^{2}\right)$ against the molecular diameter $(d)$ of the penetrant gas: $(\bigcirc), 0 \mathrm{Mrad} ;(\triangle)$, 40 Mrad; ( $\square$ ), 80 Mrad.

characteristic of the penetrant-polymer system. Thus, one may explain a linear, first-order relation between $\ln (D)$ and $1 / \bar{M}_{\mathrm{c}}$ by reference to this equation as $v_{\mathrm{f}} \propto \bar{M}_{\mathrm{c}}$. Stern et al. ${ }^{19}$ determined the constants $A$ and $B$ for $\mathrm{CO}_{2}$, $\mathrm{CH}_{4}, \mathrm{C}_{2} \mathrm{H}_{4}$, and $\mathrm{C}_{3} \mathrm{H}_{8}$-polystyrene systems and found semiempirical correlations between the constants and the diameter of a gas molecule $(d)$, where constants $A$ and $B$ are proportional to $d^{2}$ and $d$, respectively. These correlations suggest that plots of $\ln \left(D / d^{2}\right) v s . d$ 
give straight lines. As Figure 7 shows, a linear correlation exists between $\ln \left(D / d^{2}\right)$ and $d$ for irradiated and unirradiated PB films. From the slopes of the straight lines in Figure 7, the ratios of the free-volume were estimated to be $1: 0.85: 0.56$ for unirradiated PB, 40 Mradirradiated PB, and 80 Mrad-irradiated PB, respectively. Thus, reductions in permeability and diffusion coefficients are interpreted in terms of decrease in free-volume due to crosslinking.

Acknowledgements. We are indebted to Mr. Y. Hoshi of Nissin High Voltage Co., Ltd. for performing the electron beam irradiation.

\section{REFERENCES}

1. I. Sobolev, J. A. Meyer, V. Stannett, and M. Szwarc, J. Polym. Sci., 17, 417 (1955).

2. H. J. Bixler, A. S. Michaels, and M. Salame, $J$. Polym. Sci., A, 1, 895 (1963).

3. N. S. Tikhomirova, Yu. M. Malinsky, and V. L. Karpov, Vysokomol. Soedin., Ser. A, 2, 1335 (1960).

4. R. Y. M. Huang and P. J. F. Kanitz, J. Macromol. Sci., Phys., B5, 71 (1971).

5. R. W. Macdonald and R. Y. M. Huang, J. Appl.
Polym. Sci., 26, 2239 (1981).

6. R. M. Barrer and G. Skirrow, J. Polym. Sci., 3, 549 (1948); ibid., 3, 564 (1948).

7. G. J. van Amerongen, Rubber Chem. Technol., 37, 1065 (1964)

8. R. M. Barrer, J. A. Barrie, and P. S.-L. Wong, Polymer, 9, 609 (1968).

9. E. B. Trostyanskaya, A. R. Belnik, A. M. Poymanov, and P. G. Babaevskii, Vysokomol. Soedin., Ser. A, 12, 1778 (1970); ibid., Ser. A, 14, 467 (1972).

10. G. A. Gordon and A. Ravve, Polym. Eng. Sci., 20, 70 (1980).

11. O. Hayashi, T. Takahashi, Y. Matsumoto, and H. Ueno, Polym. J., 18, 487 (1986).

12. R. M. Barrer, Trans. Faraday Soc., 35, 628 (1939).

13. H. Kita, K. Okamoto, and I. Sakamoto, Radiat. Phys. Chem., 28, 393 (1986).

14. P. J. Flory, "Principle of Polymer Chemistry," Cornell University Press, New York, 1953, Chapter 13.

15. Y. Takeuchi, Nippon Gomu Kyokai Shi, 52, 481 (1979).

16. K. Toi, Y. Ohori, Y. Maeda, and T. Tokuda, J. Polym. Sci., Polym. Phys. Ed., 18, 1621 (1980).

17. A. Aitken and R. M. Barrer, Trans. Faraday Soc., 51, 116 (1955).

18. H. Fujita, A. Kishimoto, and A. Matsumoto, Trans. Faraday Soc., 56, 424 (1960).

19. S. S. Kulkarni and S. A. Stern, J. Polym. Sci., Polym. Phys. Ed., 21, 441 (1983). 